\title{
Cost Accounting of Environmental Degradation by Pollution Loss Method
}

\author{
Li Yuhang ${ }^{1,}$, , Shi Jiayi ${ }^{1}$, Liu Zhuokai ${ }^{2}$ \\ ${ }^{1}$ College of Metallurgy and Energy, North China University of Science and Technology, Tangshan, China \\ ${ }^{2}$ College of Mechanical Engineering, North China University of Science and Technology, Tangshan, China \\ Email address: \\ 951945654@qq.com (Li Yuhang),295393484@qq.com (Shi Jiayi),873093619@qq.com (Liu Zhuokai) \\ ${ }^{*}$ Corresponding author
}

\section{To cite this article:}

Li Yuhang, Shi Jiayi, Liu Zhuokai. Cost Accounting of Environmental Degradation by Pollution Loss Method. Science Journal of Energy Engineering. Vol. 7, No. 3, 2019, pp. 35-38. doi: 10.11648/j.sjee.20190703.11

Received: September 22, 2019; Accepted: September 28, 2019; Published: October 12, 2019

\begin{abstract}
The biosphere provides many natural processes to maintain a healthy and sustainable environment for human life, which is known as ecosystem services. Economic theory often disregards the impact of its decisions on the biosphere or assumes unlimited resources or capacity for its needs. However, whenever humans alter the ecosystem, we potentially limit or remove ecosystem services. While individually, these activities may seem inconsequential to the total ability of the biosphere's functioning potential, cumulatively they are directly impacting the biodiversity and causing environmental degradation. Many scholars mostly adopt Costanza's method in the evaluation of ecosystem service function. However, the evaluation of ecosystem service function is static and not spatial, which is not intuitive enough. In this paper, the cost accounting of environmental degradation using the pollution loss method is summarized. Considering that the loss caused by pollution is often unmanageable and the cost of pollution control is often different from the loss caused by pollution, the pollution loss method is adopted in the selection of pollution accounting method instead of the traditional cost method. The InVEST model is introduced when calculating specific indicators. The model is very accurate to calculate the loss of environmental damage, has great significance for our future cost of protecting the environment but also saving environmental protection.
\end{abstract}

Keywords: Environmental Degradation Costs, Pollution Loss Method, InVEST Mode

\section{Introduction}

The biosphere provides many natural processes to maintain a healthy and sustainable environment for human life, which is known as ecosystem services. Economic theory often disregards the impact of its decisions on the biosphere or assumes unlimited resources or capacity for its needs. However, whenever humans alter the ecosystem, we potentially limit or remove ecosystem services. While individually, these activities may seem inconsequential to the total ability of the biosphere's functioning potential, cumulatively they are directly impacting the biodiversity and causing environmental degradation.

Many scholars mostly adopt Costanza's method in the evaluation of ecosystem service function. However, the evaluation of ecosystem service function is static and not spatial, which is not intuitive enough. The emergence of the InVEST model makes up for this gap and makes it possible to quantitatively assess the value of ecosystem services [1]. Cost accounting of environmental degradation is of considerable significance to clarify the importance of various ecosystems, to discover the spatial distribution characteristics of ecosystems, to rationally divide ecological functional areas, and to improve ecological construction planning.

Methods and methods described herein Yi et al. are not the same [9], this paper is based on multivariate modeling more precise. Song et al. put forward relevant environmental expenditure models, but the exact dates are not good enough [2]. Zhang et al. proposed a polynomial model, focusing on multi-factor ]modeling [3]. Deng et al. and Song et al. are compared and proposed a new model. In short, our model is the best [2.4]. 


\section{Concept Explanation}

\subsection{Value of Ecosystem Services}

The value of ecosystem services is based on the asset value of natural resource bases (forests, wetlands, minerals, fish and game stocks, etc). As non-renewable resources disappear, their services become more valuable. The absolute values of ecosystems include product provision, carbon fixation, water conservation, soil conservation, biodiversity conservation, climate regulation, cultural tourism and so on.

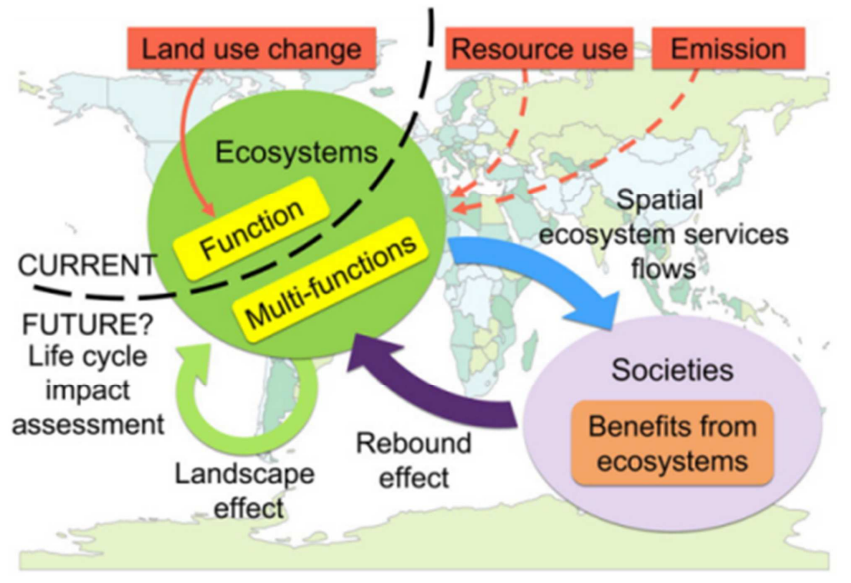

Figure 1. Concept Map of Ecosystem Services.

\subsection{Land Use Value}

As a factor of production, the land is closely related to all aspects of the economy. With rapid economic growth, land value has become an important part of GDP. As the carrier of forming and adjusting industrial structure, land plays a vital role in the layout of the whole industry. The environmental cost of land change is composed of the absolute value of ecosystem and the cost of environmental loss caused by land change. However, in the process of calculating the value of land use, the negative impact of environmental change is often neglected [3].

\subsection{InVEST Model}

InVEST Model (Integrated Valuation of Ecosystem Services and Trade-offs) is developed by Stanford University in the United States and supported by the Natural Conservation Association (TNC) and the World Wide Fund for Nature (WWF), the assessment model of ecosystem services function is designed to provide scientific decision-making and management for stakeholders by analyzing the related changes of material and value of ecosystem services under different situations [4].

\section{Cost Accounting Model for Environmental Degradation}

\subsection{Assessing the Environmental Cost of Land Development}

Since the quantitative evaluation of global ecosystem service value by Costanza in 1997, ecosystem service value assessment has been the hotspot and frontier of ecology, ecological economics, and other disciplines. Ecosystems can provide many services, such as supply services, regulatory services, and so on, which are closely linked to the healthy development of human beings and human well-being. This paper mainly evaluates the environmental cost caused by land-use change in different environments.

In this paper, the following cost calculation formulas are given. When calculating the environmental cost of actual projects, according to the actual use of land occupation, the cost factors that need to be considered are selected [5].

\subsection{Product Supply}

The direct economic value of ecosystem services is the products that can be traded directly. Using the method of market value, using the following formula to evaluate:

$$
V_{P}=\sum S_{j} \cdot V_{j} \cdot P_{j}
$$

Note: $V_{P}$ provides the total value of products for the ecosystem; $S_{j}$ is the distribution area of land type $\mathrm{j} ; V_{j}$ is the net growth or yield per unit area of land type $\mathrm{j} ; P_{j}$ is the market price of land type $\mathrm{j}$ products; $\mathrm{j}$ represents different land types.

\subsection{Carbon Sequestration}

Estimation of carbon pool based on biomass of ecosystem-based on different land, and evaluation of carbon fixation function of an ecosystem:

$$
V_{q}=\sum_{j=1}^{m} N P P_{j} \cdot 1.62 P_{c}
$$

Note: $V_{q}$ is the value of carbon fixation; $N P P_{j}$ is the net primary productivity of type $\mathrm{j}$ land; $P_{c}$ is the price of fixed carbon dioxide on the market.

\subsection{Water Conservation}

The InVEST model of water production is used to evaluate the amount of runoff regulation [6]. The InVEST model of water production is based on the Budyko curve and the mathematical model of annual rainfall, where the water runoff equals precipitation minus evapotranspiration. The formula is as follows:

$$
Y_{x j}=\left(1-\frac{A E T_{x j}}{P_{x}}\right) \cdot P_{x}
$$

Note: $\mathrm{AET}_{\mathrm{xj}}$ is the annual actual evapotranspiration of pixel $x$ in class $j$ land-use type $P x$ is the annual raindrop of pixelAET $\mathrm{xj}_{\mathrm{x}} ; \mathrm{P}_{\mathrm{x}}$ is an approximation of the Budyko curve. Based on the InVEST model, the annual water yield and its spatial distribution characteristics of different vegetation cover degrees were estimated.

\subsection{Soil Conservation}

The general soil erosion equation USLE was used to 
evaluate, including natural factors and management factors, rainfall, slope length, vegetation, soil, and land management:

$$
U S L E_{x}=R_{x} \cdot K_{x} \cdot L S_{x} \cdot C_{x} \cdot P_{x}
$$

Note: the is the soil erosion amount of grid $\mathrm{x}$; $\mathrm{Rx}$ is rainfall erosivity; $\mathrm{Kx}$ is soil erodibility; LSx is the slope-slope length factor; $\mathrm{Cx}$ is a vegetation cover factor; $\mathrm{Px}$ is a management factor.

\subsection{Value of Preserving Soil Nutrients}

$$
V_{a}=T_{h} \cdot \sum C_{i} \cdot P_{i}
$$

Note: $V_{a}$ is to keep the value of soil nutrients; $T_{h}$ is soil conservation is the nutrient species in the soil; $C_{i}$ is the class $i$ nutrient content in soil; $\mathrm{P}_{\mathrm{i}}$ is the market price for class inutrients.

\subsection{Bio-diversity Protection}

The habitat quality index in InVEST model is used to evaluate, and the formula is as follows:

$$
Q_{x j}=H_{j}\left(1-\left(\frac{D_{x j}^{Z}}{D_{x j}^{Z}+K^{Z}}\right)\right)
$$

Note: $Q_{x j}$ is the habitat quality of grid in land use and land cover $\mathrm{j} ; \mathrm{H}_{\mathrm{j}}$ is the habitat suitability of land use and land cover $\mathrm{j} ; \mathrm{D}_{\mathrm{xj}}^{\mathrm{Z}}$ is the habitat stress level of land use and land cover or habitat type $\mathrm{j}$ grid is a semi-saturation constant.

\subsection{Climatic Regulation}

The formula for calculating climate value is as follows:

$$
V=E \cdot L \cdot P / \alpha
$$

Note: $\mathrm{V}$ is to regulate climate value for the ecosystem; $\mathrm{E}$ is the transpiration of vegetation on the land; $\mathrm{L}$ is the coefficient of evaporation heat consumption; $\mathrm{P}$ is the current price of electricity; $\alpha$ is the air conditioning energy efficiency ratio.

\subsection{Culture-oriented Travel}

According to the input-output principle, the tourist's consumption expenditure can be regarded as part of the final consumption increment. Under the established pattern of an industrial association, the change of final demand will lead to the change of output value of various industrial sectors of national economy. The total amount of production stimulated by the ripple effect between industries can be obtained from the formula:

$$
U=(I-A)^{-1} H
$$

Note: $H$ is for the final travel demand vector $(\mathrm{I}-\mathrm{A})^{-1}, \mathrm{I}$ is the Leontief inverse matrix; $A$ is the Direct consumption coefficient matrix of Economic system I is a unit matrix; $U$ is the amount of production stimulated by the final tourism demand: the value of the tourism economy.

\subsection{Total Service Function of Ecosystem}

$$
V_{t}=\sum_{i=1}^{n} \sum_{j=1}^{m} V_{i j}
$$

Note: $V_{i j}$ is the value of service function in class $\mathrm{j}$ land type $\mathrm{I}$.

\section{Impact of Environmental Degradation on Land Use Cost}

When considering the impact of environmental degradation on land-use cost, the accounting of environmental pollution value includes the following aspects: water pollution value accounting, air pollution value accounting, substantial waste pollution value accounting. Pollution control cost method and pollution loss method are two methods to calculate environmental value.

The treatment cost method is a method based on cost to calculate the cost paid to avoid environmental pollution from the angle of "protection." The cost of controlling pollutants by default is equal to the harm caused by pollutant discharge.

The idea of calculating the environmental value of pollution control cost method is straightforward, that is, if all pollutants are treated, the environmental degradation will not occur; therefore, the economic value of the environmental degradation that has already occurred should be the cost required for the treatment of all pollutants. From the numerical point of view, the cost of pollution treatment is the lower limit of the value of environmental degradation.

\section{Acknowledgements}

By pricing natural resources and environmental functions, we can accurately reflect the "real value" of resource and environmental damage, and we can relatively quickly include these elements in market-oriented economic analysis.

Because the ecosystem is very complicated, the formation process of ecosystem service function is also very complicated. Numerous scholars often use the Costanza method to evaluate the ecosystem service function value. However, the evaluation of ecosystem service function is static and not specialized. The appearance of InVEST model can make up this gap and make it possible for the quantitative evaluation of ecosystem service function value to be specialized.

\section{References}

[1] Hong Juan, Li Zheng. Study on the change of ecosystem Service value of Land Reclamation: a case study of Salbrak Town, Beishangou Irrigation Dis trict, Huocheng County [J]. China's Land and Resources economy, 2016 (08): 48-53.

[2] Song Chengcheng, Chang Shun, Zhang Yutao, Xie Jin, Wang Huijie, Sun Xueliao. Evaluation of ecosystem Service function of shrub Forest in Tian shan Mountain [J]. Anhui Agricultural Science, 2017 (21): 70-74 79. 
[3] Zhang Chengxiang, Sun Jinhua, Wang Wei, Zhang Zhe. Study on ecosystem Service value and Ecological cost of Urban Road Green Space under different Management modes: a case study of Yongjia County, Zhejiang Province [J]. Resource Science, 2017 (03): 522-532.

[4] Deng Wei, Liu Hong, Li Shilong, Yuan Xingzhong, ZhangYuewei, Li Bo, Qi Jing. Dynamic changes of ecosystem Services in important Eco-functional areas of Chongqing [J]. Research in Environmental Sciences, 2015, 28 (02): 250-258.

[5] Zhao Yanhua, Su de, Li Xintong, Yang Wei, Zhao Chao, Baiyun, Bao Yang. Valuation of ecosystem Service function in Lugu Lake Basin (Yunnan Section) [J]. Journal of Southwest University (Natural Science Edition), 2017N 39 (11): 127-133.

[6] Gao L. Research on cost accounting of social economy development and environmental pollution in Guanzhong area. [J]. Acta Agriculturae Jiangxi, 2012: 91-94.

[7] Zhang Yanjun, Yang Xiaodong, Liu Yi, Zheng Dayuan, Bi Shujun. Research on the Frame of Intelligent Inspection Platform Based on Spatio-temporal Data. Computer \& Digital Engineering [J], 2019, 47 (03): 616-619+637.

[8] Han M X, Guo X M, Zhang Y S. The human capital loss of air pollution in cities, China [J]. China Environmental Science, 2006.

[9] Z. Zhao, J. Wang and Y. Liu, "User Electricity Behavior Analysis Based on K-Means Plus Clustering Algorithm," 2017
International Conference on Computer Technology, Electronics and Communication (ICCTEC), Dalian, China, 2017, pp. 484-487. doi: 10.1109/ICCTEC.2017.00111

[10] Cai C G. Valuation of health economic loss by air pollution in Beijing-comparison of contingent valuation method and human capital method. [J]. Journal of Environment \& Health, 2009: 960-961.

[11] Solarin S A, Al-Mulali U. Influence of foreign direct investment on indicators of environmental degradation $[\mathrm{J}]$. Environmental Science \& Pollution Research, 2018 (1): 1-15.

[12] Khan H H, Khan O. Income-FDI-Environmental degradation nexus for developing countries: A panel analysis of America continent [J]. Mpra Paper, 2018.

[13] Katircioglu S, Celebi A. Testing the role of external debt in environmental degradation: empirical evidence from Turkey. [J]. Environmental Science \& Pollution Research International, 2018 (2): 1-10.

[14] Alvarado R, Ponce P, Criollo A, et al. Environmental degradation and real per capita output: new evidence at the global level grouping countries by income levels [J]. Journal of Cleaner Production, 2018, 189.

[15] Hu K, Xu L, Chen W, et al. Degradation of organics extracted from dewatered sludge by alkaline pretreatment in microbial electrolysis cell $[\mathrm{J}]$. Environmental Science \& Pollution Research, 2018, 25 (2): 1-10. 